Tasova, M. and S. Yazarel, Yozgat İli Hayvansal Kaynaklı Atıkların Biyogaz ve Enerji Potansiyellerinin Belirlenmesi. International Journal of Life Sciences and Biotechnology, 2019. 2(1): p. 16-24.

\title{
Yozgat İli Hayvansal Kaynaklı Atıkların Biyogaz ve Enerji Potansiyellerinin Belirlenmesi
}

\author{
Muhammed Taşova $^{1 *}$, Serkan Yazarel ${ }^{1}$ \\ ÖZET \\ Yenilenebilir enerji kaynaklarından biri olan biyogaz hem kullanım avantajı hem de \\ ülkemizdeki ham madde kaynakları açısından önemli potansiyele sahiptir. Ülkemizde \\ organik kökenli (bitkisel, hayvansal, evsel ve kanalizasyon) atıklardan elde \\ edilebilecek biyogaz enerjisi potansiyelinin ortalama \% 40‘ $1 \mathrm{n}$ kullanmaktayız. $\mathrm{Bu}$ \\ durum mevcut biyogaz potansiyelinin daha etkin bir şekilde kullanılması ve enerji dar \\ boğazının azaltılması için bir firsat olduğu düşünülmektedir. Bu çalışmada; Yozgat \\ iline ait Türkiye İstatistik Kurumu (TÜIKK) 2013-2017 yılları arasındaki hayvan sayıs \\ (Büyükbaş, küçükbaş ve kümes) verileri kullanılarak yıllara göre yaş atık (ton/yıl), \\ kuru madde (ton/y1l), biyogaz $\left(\mathrm{m}^{3} / \mathrm{y} 1 \mathrm{l}\right), 1 \mathrm{~s} 1\left(\mathrm{GJ} / \mathrm{m}^{3}\right.$.y1l) ve elektrik enerjisi ( $\left.\mathrm{kWh} / \mathrm{y} 1 \mathrm{l}\right)$ \\ değerleri belirlenmiştir. Elde edilen bulgulara göre büyükbaş hayvanlarından kuru \\ madde ve biyogaz enerji potansiyeli 2013 yılında belirlenirken, küçükbaş ve kümes \\ hayvanlarından ise en fazla 2015 yılında olduğu tespit edilmiştir. İncelenen yıllar \\ arasında toplam hayvansal kaynaklı kuru madde ve biyogaz potansiyel değerleri en \\ fazla 2013 yılında belirlenmiş olup sırasıyla; 420.988 ton kuru madde ve \\ 13.892,63 $\mathrm{m}^{3}$ biyogaz potansiyeline sahip olduğu hesaplanmıştır.
}

MAKALE GEÇMIȘi

Geliş 14 Şubat 2019

Kabul 20 Mart 2019

\author{
ANAHTAR \\ KELIMELER \\ Yozgat, kuru \\ madde, biyogaz ve \\ enerji
}

\section{Determination of Biogas and Energy Potential of Animal Wastes in Yozgat Province}

\begin{abstract}
Biogas, which is one of the renewable energy sources, has significant potential in terms of both usage advantage and raw material resources in our country. In our country, we use an average of $40 \%$ of the biogas energy potential that can be obtained from organic origin (vegetable, animal, domestic and sewage) wastes. This is thought to be an opportunity to use the existing biogas potential more effectively and to reduce the energy bottleneck. In this study; Yozgat, the province of Turkey Statistical Institute (TSI), the number of animals between 2013 to 2017 years (cattle, sheep and poultry) years of age by years using data from waste (tons/year), dry matter (tons/year), biogas $\left(\mathrm{m}^{3} /\right.$ year $)$, heat $\left(\mathrm{GJ} / \mathrm{m}^{3}\right.$.year) and electrical energy ( $\mathrm{kWh} /$ year) values were determined. According to the findings, dry matter and biogas energy potential from cattle was determined in 2013, while it was found that it was in 2015 from small ruminants and poultry. The total value of dry matter and biogas from animal origin was determined as maximum in 2013 that 420.988 tons of dry matter and $13.892,63 \mathrm{~m}^{3}$ biogas potential has been calculated.
\end{abstract}

\author{
ARTICLE HISTORY \\ Received \\ 14 February 2019 \\ Accepted \\ 20 March 2019
}

\section{KEY WORDS}

Yozgat, dry mass, biogas and energy

\section{Giriș}

Ekonomik kalkınma ve yaşam kalitesi göstergelerinden birisi de enerji tüketim miktarıdır. Tüm dünyada olduğu gibi ülkemizde de enerji tüketim miktarları, nüfusun artması ve teknolojinin

\footnotetext{
${ }^{1}$ Tokat Gaziosmanpaşa Üniversitesi, Ziraat Fakültesi, Biyosistem Mühendisliği Bölümü

*Sorumlu yazar: muhammed.tasova@gop.edu.tr
} 
gelişmesiyle beraber her yıl artmaktadır [1]. Türkiye'nin son yıllardaki enerji üretim ve tüketim miktarlarına göre, tükettiği enerji değerinin ancak ortalama üçte birini üretebilmektedir. Ülkemizde 2020 yılına kadar hem enerji tüketim hem de üretim değerlerinde büyük bir artış olacağı ön görülmektedir [2-3]. Bu durum özellikle Türkiye gibi tarımsal potansiyeli yüksek olan ülkelerin bitkisel ve hayvansal atıklarını daha verimli bir şekilde kullanarak biyokütle enerjisine dönüştürmesi gerektiğini ortaya koymaktadır. Günümüzde bu bitkisel atıklar genellikle toprak altına gömülmekte ya da yakılarak en verimsiz şekilde kullanılarak çevresel kirliliğe yol açmaktadır.

Ülkemizde üretilen toplam biyogaz miktarının \% 85'i hayvansal kaynaklı atıklardan sağlanmaktadır [4-5]. Ayrıca ekonomik seviyenin gelişmesi ve nüfusun artmasıyla beraber hayvancılık faaliyetlerinde de bir gelişme görülmektedir. Dolayısıyla hayvansal kaynaklı atık miktarı da bu gelişmeyle birlikte artacaktır. Ancak ülkemiz hayvansal atık potansiyeli bakımından önemli değerleri sahip olmasına rağmen bundan enerjiye dönüştürme konusunda gereği kadar yararlanamamaktadır. Ülkemizde 2009 yılına ait hayvan sayısı değerlerine göre elde edilebilecek biyogaz üretim potansiyel değerleri araştırılmıştır. Çalışmaya göre hayvansal atıklardan ortalama 2.18 Giga metreküp biyogaz üretim potansiyelinin olduğu tespit edilmiştir [6].

Literatürde hayvansal ve bitkisel atıklardan bölge, yöre ve işletme bazında elde edilebilecek biyogaz miktarı ve enerji potansiyeli çalışmaları yapılmıştır. Örneğin; Türkiye'nin hayvansal ve tahıl sap atıklarının [3], Düzce ili'ne ait hayvansal atıkların [7], Hatay ili’nde ki hayvansal atıkların [8], Çanakkale ili'nde bulunan zeytin üretimi esnasında oluşan atıkların [9], Afyonkarahisar ili'ne ait bitkisel kökenli atıklardan elde edilebilecek biyogaz ve enerji potansiyel değerleri belirlenmiştir [10].

Bu çalışmada, Yozgat iline ait 2013-2017 yılları arasındaki hayvansal kaynaklı atıklardan elde edilebilecek kuru madde, biyogaz, 1sı ve elektrik enerjisi potansiyel değerleri belirlenmiştir.

\section{Materyal ve Metot}

Çalışma yeri ülkemizin $38^{\circ} 57^{\prime} 45.5^{\prime \prime} \mathrm{N} 40^{\circ} 14^{\prime} 37.4^{\prime \prime N}$ Kuzey enlemleri ile 34 04' 23.7"E 36 09' 25.0"E Doğu boylamları arasında yer almaktadır [11]. Yozgat, İç Anadolu Bölgesinde yer alan bir il olmasının yanında, Çekerek, Aydıncık ve Kadışehri ilçelerinin konumları açısından da Karadeniz Bölgesinde yer almaktadır. Yozgat ili Nüfusu: 421.041 kişi olup bunların, \% 74.31'i şehirde yaşamaktadır. İlin yüzölçümü 13.690 km²'dir (Şekil 1) [12]. 


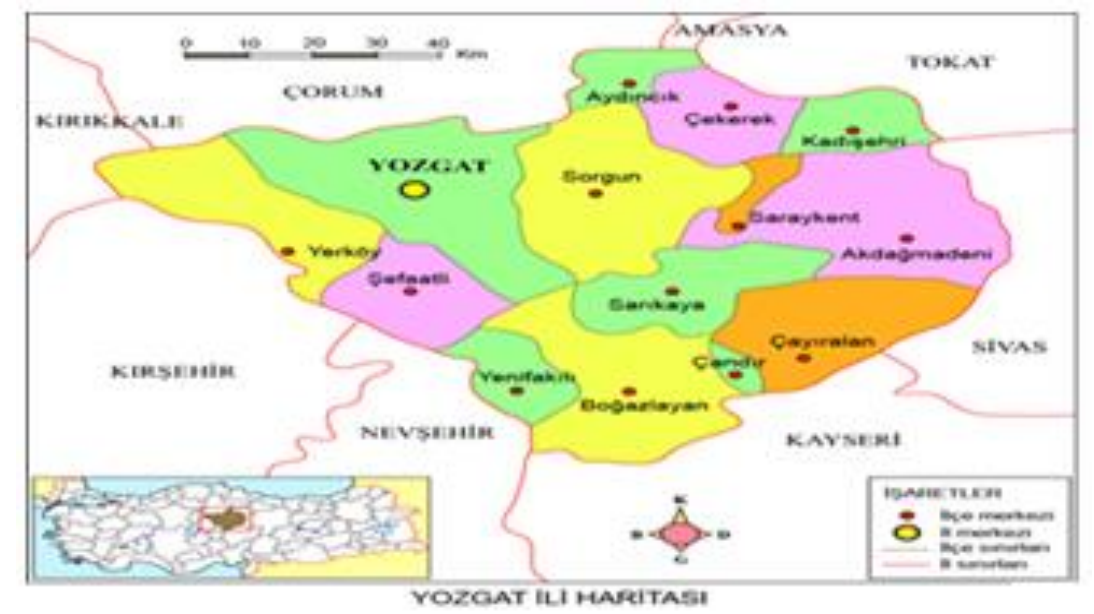

Şekil 1 Yozgat ilinin konumu [13]

Yozgat ili'nin tarım, orman, çayır-mera ve tarım dışı alan dağılım büyüklükleri (da) ve oluşturdukları \%'lik oranları tablo 1'de verilmiştir [14].

Tablo 1 Yozgat ilinin arazi dağılımı

\begin{tabular}{lrr}
\hline Arazinin Cinsi & Yüzölçümü (ha) & Toplam Araziye oranı (\%) \\
\hline Tarıma elverişli alan & 779.440 & 58.08 \\
Orman alanı & 268.637 & 20.02 \\
Çayır-mera alanı & 260.153 & 19.39 \\
Tarım dışı alan & 33.675 & 2.51 \\
Toplam & $\mathbf{1 . 3 4 1 , 9 0 5}$ & $\mathbf{1 0 0 . 0 0}$ \\
\hline
\end{tabular}

Tablo 1'e göre Yozgat ili'nin arazi dağılımında yüzde olarak en büyük payı tarım alanları oluştururken, en küçük payı ise tarım dışı alanlar oluşturmaktadır.

\section{Çalışma alanındaki mevcut hayvan sayısı}

Yozgat ili ne ait 2013-2017 yıllarına ait hayvan sayıları Türkiye İstatistik Kurumu (TÜİK) resmi sitesinden temin edilerek belirtilen yıllara ait toplam hayvan sayıları içerisindeki \% oran dağılımları hesaplanmıştır (Tablo 2).

Tablo 2 Yozgat ili hayvan sayıları [15]

\begin{tabular}{llrr}
\hline Yıllar & $\begin{array}{l}\text { Hayvan } \\
\text { grupları }\end{array}$ & Hayvan sayıları & $\begin{array}{r}\text { Toplam hayvan } \\
\text { sayısına oranı } \\
(\mathbf{\%}) *\end{array}$ \\
\hline \multirow{2}{*}{2013} & Büyükbaş & 273.457 & 20.04 \\
& Küçükbaş & 377.251 & 20.32 \\
& Kümes & 714.074 & 59.64 \\
& Toplam & $\mathbf{1 . 3 6 4 , 7 8 2}$ & $\mathbf{1 0 0 . 0 0}$ \\
\cline { 2 - 4 } & Büyükbaş & 247.833 & 16.99 \\
\hline
\end{tabular}




\begin{tabular}{rlrr}
\hline 2014 & Küçükbaş & 396.063 & 27.16 \\
& Kümes & 814.459 & 55.85 \\
& Toplam & $\mathbf{1 . 4 5 8 , 3 5 5}$ & $\mathbf{1 0 0 . 0 0}$ \\
\cline { 2 - 4 } 2015 & Büyükbaş & 244.381 & 14.38 \\
& Küçükbaş & 407.831 & 23.99 \\
& Kümes & 1047.705 & 61.63 \\
& Toplam & $\mathbf{1 . 6 9 9 , 9 1 7}$ & $\mathbf{1 0 0 . 0 0}$ \\
\cline { 2 - 4 } 2016 & Büyükbaş & 206.083 & 16.28 \\
& Küçükbaş & 312.272 & 24.66 \\
& Kümes & 747.825 & 59.06 \\
& Toplam & $\mathbf{1 . 2 6 6 , 1 8 0}$ & $\mathbf{1 0 0 . 0 0}$ \\
\cline { 2 - 4 } 2017 & Büyükbaş & 235.570 & 18.35 \\
& Küçükbaş & 348.629 & 27.15 \\
& Kümes & 699.823 & 54.50 \\
& Toplam & $\mathbf{1 . 2 8 4 , 0 2 2}$ & $\mathbf{1 0 0 . 0 0}$ \\
\hline
\end{tabular}

* Hesaplanan değer

Tablo 2'ye göre, Yozgat ili'ne ait belirlenen yıllar içerisinde en fazla toplam hayvan sayısı 1.699,917 ile 2015 yılındayken en az hayvan sayısı ise 1.266,180 ile 2016 y1lında olduğu görülmektedir. Belirlenen tüm yıllarda kümes hayvan sayıları diğer büyük ve küçükbaş hayvan sayılarına göre daha fazla olmuştur. \%'lik oran açısından incelendiğinde \% 61.63 ile en fazla kümes hayvan sayısı oranı 2015 yılında olduğu görülmektedir. Hayvansal atıklardan elde edilebilecek biyogaz potansiyel değerlerinin belirlenmesinde kullanılan matematiksel eşitlikler; $Y A P=T H S x H B A$

Burada; YAP, yıllık yaş atık miktarı (ton/yıl); THS, toplam hayvan sayısı (n); HBA, hayvan türüne göre yıllık yaş atık miktarı (ton/yıl); küçük hayvanlar için kullanılan sabit değer.

$K G M=Y A P x \boldsymbol{x}$

Burada; KGM, yıllık katı gübre miktarı (ton/yıl); $\Theta$, hayvanların ağıl dışında dolaşması ve atıktaki suyun buharlaşmasına bağlı katsayı.

$B \ddot{U} P=K G M x H B \ddot{U} B$

Burada; BÜP, biyogaz üretim potansiyeli (m3/yıl); HBÜB, hayvan türüne göre y1llık biyogaz üretim sabit değeri.

\section{$B S I=B \ddot{U} P \times Y \times 0.0000041868$}

Burada; BSI, biyogazdan üretilebilecek 1sı miktarı (GJ/m³.y1l); $\mathrm{X}$, sağlanılan 1sı enerjisini kcal cinsinden değeri; 0.0000041868 katsayısı birimi GJ 'e dönüştürmek için kullanılan katsayı.

$B S E=B \ddot{U} P \boldsymbol{x} f$

Burada; BSE, biyogazdan üretilebilecek elektrik enerjisi miktarı (kWh/yıl); $f, 1 \mathrm{~m} 3$ biyogazdan elde edilebilecek elektrik enerji değeri.

$H S=B S E / 3036$ 
Burada; HS (n), hane sayısı; $3036(\mathrm{kWh} / \mathrm{y} 1 \mathrm{l})$, dört kişilik hanenin yıllık tükettiği elektrik enerji değeri.

Hayvan gruplarına göre toplam yaş atık potansiyel miktarları Akbulut ve Dikici'nin 2004 yılında yaptıkları çalışma ile Gürel'in 2010 yılında yapmış olduğu çalışmalardaki ortak yönteme göre belirlenmiştir [16-17]. Yıllık ortalama kuru madde potansiyel değeri ise Baran ve arkadaşlarının 2017 yılında yaptıkları çalışmada belirtilen yönteme göre tespit edilmiştir [18]. Belirlenen yıllık ortalama biyogaz potansiyel miktarları da Altıkat ve Çelik'in 2012 yılında yapmış oldukları çalışma izledikleri yönteme bulunmuştur [19]. Hesaplanan biyogaz potansiyelinin 1sısal $\left(\mathrm{GJ} / \mathrm{m}^{3}\right.$.yıl) ve elektriksel enerji değerleri ise Taşova'nın 2017 yılında yapmış olduk çalışma belirttiği yönteme göre belirlenmiştir [20].

\section{Bulgular ve Tartışma}

\section{Belirlenen Hayvansal Gübre ve Biyogaz Miktarı}

Tablo 2' deki Yozgat İli' ne ait hayvan sayısı değerlerine göre 2013-2017 y1lları arasındaki \%, lik yaş atık potansiyel oranları belirlenmiştir (Şekil 2).

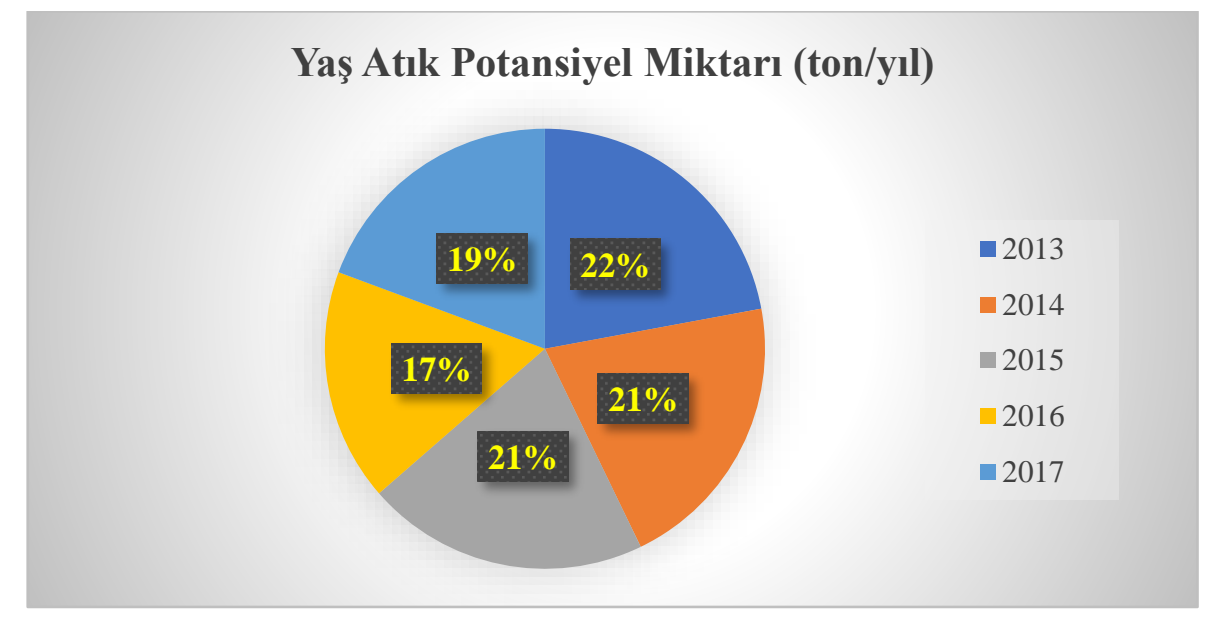

Şekil 2 2013-2017 yılları arasında belirlenen toplam yaş atık potansiyelinin yıllara göre \% oranları

Şekil 2' e göre son beş yıldaki toplam hayvan sayısı değerlerine göre elde edilebilecek en büyük yaş atık potansiyel oranı \% 22 ile 2013 yılında olduğu belirlenirken, en küçük oran ise \% 17 ile 2016 yılında olduğu belirlenmiştir.

Belirtilen yıllara göre hesaplanan yaş atık miktarlarından elde edilebilecek ortalama kuru madde ve biyogaz potansiyel miktarları belirlenmiştir (Tablo 3). 
Tablo 3 Belirlenen toplam kuru madde ve biyogaz potansiyel miktarları

\begin{tabular}{llrr}
\hline Yıllar & Hayvan grupları & $\begin{array}{r}\text { Kuru madde } \\
\text { potansiyeli } \\
\text { (ton/yl) }\end{array}$ & $\begin{array}{r}\text { Biyogaz } \\
\text { potansiyeli } \\
\left(\mathbf{m}^{3} / \mathbf{y l}\right)\end{array}$ \\
\hline \multirow{2}{*}{2013} & Büyükbaş & 327.820 & $10.818,068$ \\
& Küçükbaş & 87.932 & $2.901,928$ \\
& Kümes & 5.231 & 172.633 \\
2014 & Toplam & $\mathbf{4 2 0 . 9 8 3}$ & $\mathbf{1 3 . 8 9 2 , 6 2 9}$ \\
\cline { 2 - 4 } & Büyükbaş & 297.102 & $9.804,373$ \\
& Küçükbaş & 92.322 & $3.046,635$ \\
& Kümes & 5.967 & 196.902 \\
& Toplam & $\mathbf{4 0 0 . 3 9 1}$ & $\mathbf{1 3 . 0 4 7 , 9 1 0}$ \\
\cline { 2 - 4 } 2015 & Büyükbaş & 292.964 & $9.667,810$ \\
& Küçükbaş & 95.065 & $3.137,158$ \\
& Kümes & 7.675 & 180.793 \\
& Toplam & $\mathbf{3 9 5 . 7 0 4}$ & $\mathbf{1 2 . 9 8 5 , 7 6 1}$ \\
\cline { 2 - 4 } 2017 & Büyükbaş & 247.052 & $8.152,726$ \\
& Küçükbaş & 72.791 & $2.402,090$ \\
& Kümes & 5.479 & 180.793 \\
& Toplam & $\mathbf{3 2 5 . 3 2 2}$ & $\mathbf{1 0 . 7 3 5 , 6 0 9}$ \\
\cline { 2 - 4 } & Büyükbaş & 282.401 & $9.319,243$ \\
& Küçükbaş & 81.265 & $2.681,759$ \\
& Kümes & 5.127 & 169.188 \\
& Toplam & $\mathbf{3 6 8 . 7 9 3}$ & $\mathbf{1 2 . 1 7 0 , 1 9 0}$ \\
\hline
\end{tabular}

Tablo 3' e göre 2013-2017 yılları arasındaki hayvan gruplarına göre, toplam kuru madde ve biyogaz potansiyel miktarları belirlenmiştir. Değerlere göre biyogaz potansiyel miktarının oluşmasında kuru madde miktarı ve hayvan grubunun etkili olduğu görülmektedir. Yıllara göre en yüksek kuru madde ve biyogaz potansiyel miktarları 2013 y1lında sirasıyla; 420.983 ton/y1 ve $13.892,629 \mathrm{~m}^{3} / \mathrm{y} 1 \mathrm{l}$ olarak belirlenirken, en düşük kuru madde ve biyogaz potansiyel miktarları ise 2016 yılında oluşurken sırasıyla; 325.322 ton/y1l ve 10.735,609 m³/yıl olarak belirlenmiştir.

Taşova'nın 2018 yılında yapmış oldu çalışmaya göre yerel bir hayvansal üretim çiftliğine ait yaş atık, kuru madde ve biyogaz potansiyeli değerlerini belirlediği çalışmasında, işletmenin y1llık ortalama 350 ton yaş atık, 117 ton kuru madde, $6760 \mathrm{~m}^{3}$ biyogaz elde edilebileceğini belirlemiştir [21]. Tınmaz Köse'nin Trakya bölgesi için yapmış olduğu çalışmada, TÜİK'na ait 2015 yılı küçükbaş hayvan sayısı verilerini kullanarak, ortalama $819.192 \mathrm{~m}^{3}$ metan gazı elde edilebileceğini tespit etmişlerdir [22]. Baran ve arkadaşlarının Adıyaman ili’nde ki küçükbaş hayvanlarından yıllık ortalama 214.006.800 ton gübre bu gübrelerden ise ortalama 8.274.929.600 $\mathrm{m}^{3}$ biyogaz elde edilebileceğini hesaplamışlardır [18]. Doruk ve Bozdeveci'nin 2017 y1lı için Denizli ili'nde bulunan hayvansal atıklardan yıllık ortalama $125.449 \mathrm{~kg}$ yaş atık ve $70.16 \mathrm{~m}^{3}$ biyogaz elde edilebileceğini ifade etmişlerdir [23]. Taşova ise, Tokat ili’ne ait 
2010-2014 yılları arasındaki kümes hayvanlarına ait yıllık ortalama yaş atık ve biyogaz potansiyel değerlerini çalışmasında sırasıyla; $6.052,60 \mathrm{~kg}$ ve $472.095,60 \mathrm{~m}^{3}$ olarak belirlemiştir [20].

\section{Biyogaz potansiyel miktarının enerji değerleri}

Yozgat ili'ne ait 2013-2017 yıllarına arasındaki hayvan sayısı verilerine göre belirlenen biyogaz potansiyel miktarının ısı ve elektrik enerjisi değerleri hesaplanmıştır (Tablo 4).

Tablo 4 Belirlenen 1sı ve elektrik enerjisi değerleri

\begin{tabular}{|c|c|c|c|}
\hline Yillar & Hayvan grupları & $\begin{array}{r}\text { Isı enerjisi potansiyeli } \\
\left(G J / \mathbf{m}^{3} \cdot \text { yıl }\right)\end{array}$ & $\begin{array}{r}\text { Elektrik enerjisi } \\
\text { potansiyeli } \\
(\mathrm{kWh} / \mathrm{yl})\end{array}$ \\
\hline \multirow{4}{*}{2013} & Büyükbaş & 235.524 & $50.844,921$ \\
\hline & Küçükbaş & 63.179 & $13.639,061$ \\
\hline & Kümes & 3.758 & 811.376 \\
\hline & Toplam & 302.461 & $65.295,358$ \\
\hline \multirow{3}{*}{2014} & Büyükbaş & 213.455 & $46.080,551$ \\
\hline & Küçükbaş & 66.329 & 19.319 .186 \\
\hline & Kümes & 4.287 & 925.439 \\
\hline \multirow{5}{*}{2015} & Toplam & 284.071 & $66.325,176$ \\
\hline & Büyükbaş & 210.481 & $45.438,708$ \\
\hline & Küçükbaş & 68.300 & $14.744,644$ \\
\hline & Kümes & 5.514 & $11.904,618$ \\
\hline & Toplam & 284.295 & 72.087,970 \\
\hline \multirow{3}{*}{2016} & Büyükbaş & 177.496 & $38.317,812$ \\
\hline & Küçükbaş & 52.297 & $11.289,823$ \\
\hline & Kümes & 3.936 & 849.726 \\
\hline \multirow{5}{*}{2017} & Toplam & 233.729 & $50.457,361$ \\
\hline & Büyükbaş & 202.893 & $43.800,444$ \\
\hline & Küçükbaş & 58.386 & $12.604,267$ \\
\hline & Kümes & 3.683 & 795.183 \\
\hline & Toplam & 264.962 & $57.199,894$ \\
\hline
\end{tabular}

Tablo 4'e göre 2013-2017 yılları arasında belirlenen biyogaz potansiyel miktarının 1s1 ve elektrik enerjisi potansiyel değerlerine göre en yüksek 1s1 enerjisi değeri $302.461 \mathrm{GJ} / \mathrm{m}^{3}$.y1l ile 2013 yılında elde edilebilirken, en düşük ise $233.729 \mathrm{GJ} / \mathrm{m}^{3}$.y1l değeri ile 2016 yılında elde 
edilebileceği belirlenmiştir. Elektrik enerjisi potansiyel değerleri incelendiğinde ise en yüksek değer 72.087,97 kWh/yıl ile 2015 yılında elde edilebilirken, en küçük değer ise 50.457,36 kWh/yıl ile 2016 yılında elde edilebileceği belirlenmiştir.

Belirlenen değerlere göre, hayvan sayılarının değişmesiyle beraber çok daha fazla enerji kapasitesi değerlerine ulaşılabilir. Polatcı ve arkadaşlarının yapmış oldukları çalışmalarında biyogaz elde etmek için kurulan yerel bir tesisin aylık ortalama biyogaz enerjisi değerinin 1.585.85 MW arasında değiştiğini belirlemişlerdir [24]. Alibaş ve arkadaşlarının Diyarbakır ili'ne ait 2010-2014 yılları arasındaki hayvan sayılarına göre belirledikleri yıllık ortalama biyogaz miktarından elde edilebilecek elektrik enerjisi değerinin $96.05 \mathrm{GWh}$ olduğunu ifade etmişlerdir [25]. Doruk ve Bozdeveci'nin yaptıkları çalışmalarında Denizli ili'n de bulunan hayvansal kaynaklı atıklardan yıllık ortalama 329 milyon kWh elektrik enerjisi elde edilebileceğini tespit etmişlerdir [23]. Taşova'nın yaptığı çalışmada, küçükbaş hayvanlarından elde edilebilecek ısı ve elektrik enerjisi değerlerini sırasıyla; $147 \mathrm{GJ} / \mathrm{m}^{3}$.yıl ve $31772 \mathrm{kWh} / \mathrm{y}$ 1l olarak çalışmasında belirlemiştir [21].

\section{Sonuç ve Öneriler}

Yozgat ili'ne ait 2013-2017 yılları arasındaki hayvan sayısı değerlerine göre;

1) Kuru madde ve biyogaz potansiyel miktarlarının en fazla olduğu yıl 2013 ve en az olduğu y1l ise 2016 olduğu belirlenmiştir.

2) Biyogaz potansiyel miktarından elde edilebilecek 1sı enerjisi potansiyel değeri en fazla 2013 y1lındayken, en az ise 2016 y1lında olduğu belirlenmiştir.

3) Elektrik enerjisi potansiyel değerleri açısından ise sırasıyla en fazla ve en az olduğu yıllar 2015 ve 2016 yılları olduğu belirlenmiştir.

Çalışma kapsamında yapılacak öneri olarak ise; Yozgat ili'ne ait yıllık ortalama elektrik enerjisi tüketim miktarının 600-700 bin kWh olduğu bir durumda, yapılan bu çalışmada hayvansal atıklardan elde edilebilecek yıllık ortalama 60 bin kWh'lik elektrik enerjisi değerinin önemli olduğu düşünülmektedir. Hayvansal atıklardan kazanılabilecek enerji değerinin, Yozgat ili için yıllık elektrik enerjisi tüketim miktarının ortalama \% 10'luk kısmını karşılayabilmesi açısından da ayrı bir önem kazanmaktadır. Yozgat ili’nde bulunan hayvan sayılarında sonraki yıllarda gözlemlenecek herhangi bir değişim durumunda hesaplanan bu teorik değerlerinde değişeceği göz önünde bulundurulmalıdır.

\section{Kaynaklar}

1 Koç E, Kaya K (2015). Enerji Kaynakları-Yenilenebilir Enerji Durumu. Mühendis ve Makine Dergisi. 56 (688). 36-47. 
Anonim (2011). Türkiye'de Biyogaz Yatırımları İçin Geçerli Koşulların ve Potansiyelin Değerlendirilmesi. Türk-Alman Biyogaz Projesi. T.C. Çevre ve Şehircilik Bakanlığı. Ankara. (Erişim Tarihi: 15.03.2018).

Aybek A, Üçok S, İspir MA, Bilgili ME (2015). Türkiye'de Kullanılabilir Hayvansal Gübre ve Tahıl Sap Atıklarının Biyogaz ve Enerji Potansiyelinin Belirlenerek Sayısal Haritalarının Oluşturulması. Tekirdağ Ziraat Fakültesi Dergisi, 12(03).

Türe S, Özdoğan S, Saygin Ö (1994). Sixth energy congress of Turkey. World Energy Council-Turkish National Committee, Proceedings of Technical Session 1, İzmir.

5 Demirbaş A (2001). Energy balance, energy sources, energy policy, future developments anad energy investments in Türkey. Energy Conservation and Management, 42, 10, 1239-1258.

6 Onurbaş Avcıoğlu A, Türker U (2012). Status and potential of biogas energy from animal wastes in Turkey. Renewable and Sustainable Energy Reviews 16, 1557-1561.

7 Yürük F, Erdoğmuş P (2015). Düzce İlinin Hayvansal Atıklardan Üretilebilecek Biyogaz Potansiyeli ve K-Means Kümeleme İle Optimum Tesis Konumunun Belirlenmesi. İleri Teknoloji Bilimleri Dergisi 4 (1), 47-56.

8 Karaca C (2017). Hatay İlinin Hayvansal Gübre Kaynağından Üretilebilir Biyogaz Potansiyelinin Belirlenmesi. Mustafa Kemal Üniversitesi Ziraat Fakültesi Dergisi, 22(1), 34-39.

9 Sümer SK, Çiçeki G, Say SM (2016). Çanakkale İlinde Zeytin Üretimi Artık Potansiyelinin Belirlenmesi ve Değerlendirme Olanaklarının Araştııılması. Tarım Makinaları Bilimi Dergisi, 12 (2), 103-111.

10 Külcü R (2016). Afyonkarahisar İlinin Tarımsal Biyokütle Potansiyelinin İncelenmesi. Akademia Mühendislik ve Fen Bilimleri Dergisi. 1 (2). 1-9.

11 Anonim (2018a). Coğrafya Eğitimi. https://www.cografyaegitimi.biz/tags/yozgat/ (Erişim Tarihi: 11.10.2018).

12 Anonim (2018b). Yozgat il. https://tr.wikipedia.org/wiki/Yozgat_(il) (Erişim Tarihi: 11.10.2018).

Anonim (2018c). Gebze Akçay Kırtasiye Kitap. https://akcaykirtasiye.tr.gg/ (Erişim Tarihi: 11.10.2018). Yozgat İl Tarım Müdürlüğü (2009). Yozgat Tarım Hayvancılık Ve Gıda Sektörel Çalışma Grubu Raporu. http://oran.org.tr (Erişim Tarihi: 16.10.2018).

15 Türkiye İstatistik Kurumu (2017). http://www.tuik.gov.tr/PreTablo.do?alt_id=1001 (Erişim Tarihi: 16.10.2018).

Akbulut A, Dikici A (2004). Elazığ İlinin Biyogaz Potansiyeli ve Maliyet Analizi. Doğu Anadolu Bölgesi Araştırmaları Dergisi, 2 (2), 36-41.

Gürel A (2010). Tekirdağ İlinin Keşfedilmeyen Değerlerinden Biyogaz Potansiyeli. Tekirdağ Değerleri Sempozyumu, ISBN: 9786054265121, 60-69.

Baran MF, Lüle F, Gökdoğan O (2017). Adıyaman İlinin Hayvansal Atıklardan Elde Edilebilecek Enerji Potansiyeli. Türk Tarım ve Doğa Bilimleri Dergisi, 4 (3), 245-249.

Altıkat S, Çelik A (2012). Iğdır İlinin Hayvansal Atık Kaynaklı Biyogaz Potansiyeli. Iğdır Üniversitesi Fen Bilimleri Enstitü Dergisi, 2(1), 61-66.

Taşova M (2017). Kümes Hayvanları Atıklarının Biyogaz Üretim Potansiyelinin Belirlenmesi: Tokat İli Örneği. Kafkas Üniversitesi Fen Bilimleri Enstitüsü Dergisi, 10 (2): 287-294.

Taşova M (2018). Yerel Bir Küçükbaş Hayvancılık İşletmesi'nin Biyogaz Potansiyelinin Belirlenmesi. Türk Tarım ve Doğa Bilimleri Dergisi, 5 (3): 268 - 272.

Tınmaz Köse E (2016). Trakya bölgesinde hayvan gübrelerinin biyogaz enerji potansiyelinin belirlenmesi ve sayısal haritaların oluşturulması. Pamukkale Üniversitesi Mühendislik Bilimleri Dergisi, 23(6): 762772.

Doruk İ, Bozdeveci A (2017). Denizli İlinin Kırsal Kesimlerinde Hayvansal Kaynaklı Atıklardan Biyogaz Potansiyelinin Belirlenmesi. Iğdır Üniversitesi Fen Bilimleri Enstitü Dergisi, 7 (3), 181-186.

Polatcı H, Taşova M, Kasap A, Yüksel M (2016). Biogas Production Potential of Solid Wastes: A Research Experience. Tarım Bilimleri Araştırma Dergisi, 9(1): 48-50. 